\title{
A worldwide correlation of lactase persistence phenotype and genotypes
}

Yuval $\operatorname{Itan}^{1,2^{*}}$, Bryony L Jones ${ }^{1}$, Catherine JE Ingram ${ }^{1}$, Dallas M Swallow ${ }^{1}$, Mark G Thomas ${ }^{1,2,3}$

\begin{abstract}
Background: The ability of adult humans to digest the milk sugar lactose - lactase persistence - is a dominant Mendelian trait that has been a subject of extensive genetic, medical and evolutionary research. Lactase persistence is common in people of European ancestry as well as some African, Middle Eastern and Southern Asian groups, but is rare or absent elsewhere in the world. The recent identification of independent nucleotide changes that are strongly associated with lactase persistence in different populations worldwide has led to the possibility of genetic tests for the trait. However, it is highly unlikely that all lactase persistence-associated variants are known. Using an extensive database of lactase persistence phenotype frequencies, together with information on how those data were collected and data on the frequencies of lactase persistence variants, we present a global summary of the extent to which current genetic knowledge can explain lactase persistence phenotype frequency.

Results: We used surface interpolation of Old World lactase persistence genotype and phenotype frequency estimates obtained from all available literature and perform a comparison between predicted and observed trait frequencies in continuous space. By accommodating additional data on sample numbers and known false negative and false positive rates for the various lactase persistence phenotype tests (blood glucose and breath hydrogen), we also apply a Monte Carlo method to estimate the probability that known lactase persistence-associated allele frequencies can explain observed trait frequencies in different regions.

Conclusion: Lactase persistence genotype data is currently insufficient to explain lactase persistence phenotype frequency in much of western and southern Africa, southeastern Europe, the Middle East and parts of central and southern Asia. We suggest that further studies of genetic variation in these regions should reveal additional nucleotide variants that are associated with lactase persistence.
\end{abstract}

\section{Background}

An estimated $65 \%$ of human adults (and most adult mammals) downregulate the production of intestinal lactase after weaning. Lactase is necessary for the digestion of lactose, the main carbohydrate in milk [1], and without it, milk consumption can lead to bloating, flatulence, cramps and nausea [2]. Continued production of lactase throughout adult life (lactase persistence, LP) is a genetically determined trait and is found at moderate to high frequencies in Europeans and some African, Middle Eastern and Southern Asian populations (see Additional File 1 and Figure 1).

The most frequently used non-invasive methods for identifying the presence of intestinal lactase are based

\footnotetext{
* Correspondence: y.itan@ucl.ac.uk

${ }^{1}$ Research Department of Genetics, Evolution and Environment, University College London, London WC1E 6BT, UK
}

upon detecting digestion products of lactose produced by the subject (Blood Glucose, BG) or gut bacteria (Breath Hydrogen, BH). For both methods a lactose load is administered to the subject following an overnight fast. In individuals producing lactase this leads to a detectable increase in blood glucose. In individuals who are not producing lactase, the undigested lactose will pass into the colon where it is fermented by various gut bacteria, producing fatty acids and various gases, particularly hydrogen. Hydrogen passes through the blood into the lungs and so can be detected in the breath using a portable hydrogen analyser. Both the BG and the $\mathrm{BH}$ tests have asymmetric type I and type II error rates. Thus any study seeking association between a particular polymorphism and LP should take these error rates into account. In addition it should be noted that while in most cases the presence/absence of intestinal 


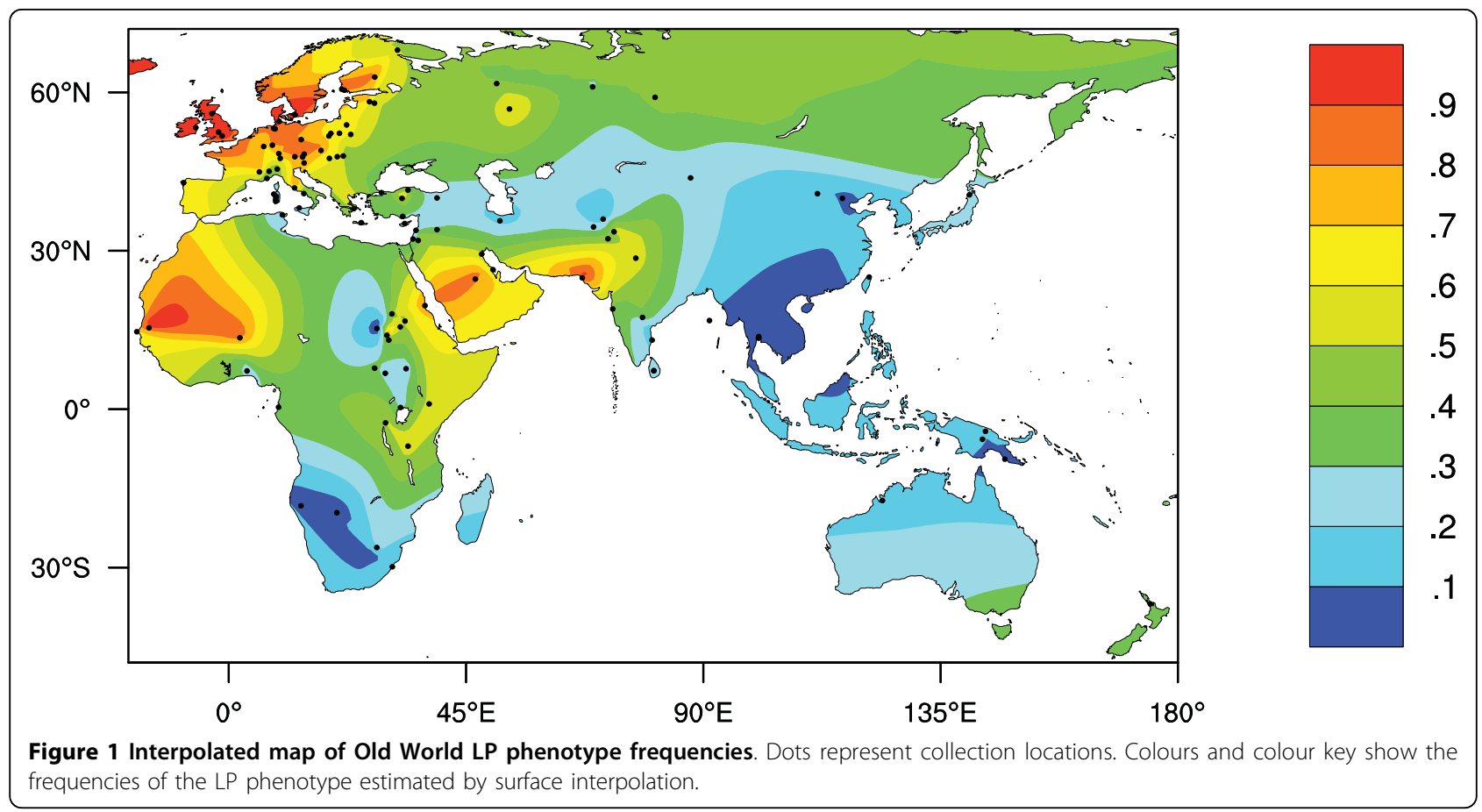

lactase in an adult is likely to be genetically determined, the loss of lactase can also be caused by gut trauma such as gastroenteritis [3-6]. Other non-invasive methods for detecting the presence/absence of lactase include assaying for urine galactose and detecting metabolites of Carbon-14-labelled lactose. These methods are rarely used today. The most reliable method is intestinal biopsy, which provides a direct determination of intestinal lactase activity. However, this procedure is very rarely used for diagnosing healthy individuals because of its invasive nature [7].

With the recent discovery of nucleotide changes associated with LP comes the prospect of direct genetic tests for the trait [8-10]. However, it has become clear that there are multiple, independently derived LP-associated alleles with different geographical distributions $[1,8,11,12]$. LP is particularly common in Europe and certain African and Middle Eastern groups. As a consequence these are the regions where most genetic studies have been focused and all currently known LP alleles have been identified $[7,11,12]$. The first allelic variant that was shown to be strongly associated with increased lactase activity is a $\mathrm{C}>\mathrm{T}$ change 13,910 bases upstream of the LCT gene in the $13^{\text {th }}$ intron of the MCM6 gene [13]. Functional studies have indicated that this change may affect lactase gene promoter activity and increase the production of lactase-phlorizin hydrolase mRNA in the intestinal mucosa [14-17] but, as with all LP-associated variants, there remains the possibility that linkage to as yet unknown causative nucleotide changes may explain observed associations. Haplotype length conservation [18], linked microsatellite variation [19] and ancient DNA analysis from early European farmers [20] later confirmed that this allele has a recent evolutionary origin and had been the subject of strong positive natural selection. Furthermore, a simulation model of the origins and evolution of lactase persistence and dairying in Europe has inferred that natural selection started to act on an initially small number of lactase persistent dairyers around 7,500 BP in a region between Central Europe and the northern Balkans, possibly in association with the Linearbandkeramik culture [21]. Another simulation study has inferred that it is likely that lactase persistence selective advantage was not constant over Europe, and that demography was a significant element in the evolution and spread of European lactase persistence [22].

However, the presence of this allele could not explain the frequency of LP in most African populations [8]. Further studies identified three additional variants that are strongly associated with LP in some African and Middle Eastern populations and/or have evidence of function, all are upstream of the $L C T$ gene in the $13^{\text {th }}$ intron of the MCM6 gene: $-13,907 * \mathrm{G},-13,915^{*} \mathrm{G}$ and $-14,010 * \mathrm{C}$ $[11,12,23,24]$. Where data were sufficient, some of these alleles also showed genetic signatures of a recent origin and strong positive natural selection [12,23].

Although at least four strong candidate causative alleles have been identified, only a small number of populations have been studied, and those are confined to Europe, Africa and the Middle East. It is therefore 
unlikely that all LP-associated or LP-causing alleles are currently known. As a consequence, genetic tests based on current knowledge would underestimate the frequency of LP in most world populations. As part of the first study to seek a genetic explanation for the distribution of LP in Africa [8], a statistical procedure (GenoPheno) was developed to test if the frequency of an LPassociated allele could explain reported LP frequency in ethnically matched populations. Crucially, this statistical procedure was designed to account for sampling errors and the asymmetric type I and type II error rates associated with different phenotype tests (BH and BG).

In this study we have sought to extend this approach to the whole of the Old World. However, while there is a rich literature on the frequencies of LP in different geographic regions [1] and a growing body of publications reporting the frequencies of candidate LP-causing alleles, in most cases the genetic and phenotypic data are not from the same people and often not of closely neighbouring groups. Thus, characterization of the extent to which LP frequency can be explained by current knowledge of LP-associated genotype frequencies is limited to populations where both data types are available. To overcome this problem we performed surface interpolation of various data categories (genetic, phenotypic, sample numbers, phenotype tests used and their associated error rates) and applied the statistical procedures described on a fine grid covering the Old World landmass. This has allowed us to identify regions where reported LP-associated allele frequencies are insufficient to explain the presence of LP. These regions should be good candidates for future genotype/phenotype studies.

\section{Methods}

Data

Our global LP phenotype dataset consists of 112 locations [1] (see Additional File 1). These data were carefully selected from a large literature on LP frequencies so as to remove data collected from (1) children, (2) patients selected for likely lactose intolerance, (3) family members, and (4) people with twentieth/twenty-first century immigrant status. Genotype data was obtained for 132 locations where the frequency of the $-13,910$ C> T allele had been estimated [7,8,11,18,25-27], and from 61 locations where the frequency of all 4 currently known LP associated allelic variants had been estimated [12,23,26,28] (see Additional File 2). These data were carefully selected from a large literature on LP frequencies so as to remove data collected from (1) patients selected for likely lactose intolerance, (2) family members, and (3) people with twentieth/twenty-first century immigrant status. Where there was more than one dataset for a particular location (for either genotype or phenotype data), a weighted average frequency was calculated. The type I and type II error rates used were $8.621 \%$ and $6.849 \%$, respectively, for BG and $6.818 \%$ and $4.167 \%$, respectively, for $\mathrm{BH}$ [8]. Predicted LP frequencies, from the LP genotype frequencies, were calculated by assuming Hardy-Weinberg equilibrium and dominance (see Additional File 2).

The geographic space explored was from longitude -19 to 180 , and from latitude -48 to 72 .

\section{Surface Interpolation}

To estimate the distribution of LP and LP-associated allele frequencies in continuous space, from irregularly spaced data, surface interpolation was performed using the Natural Neighbour algorithm [29,30], as implemented in the PyNGL module of the Python programming language [31-33]. Briefly, this algorithm first divides a 2dimentional space into polygons according to the locations of the observed data points, then estimates the value at locations for which data is absent by weighting each of the neighbouring locations by their relative overlap.

\section{Quantitative Difference Correlation Analysis}

We also performed an analysis to quantify the difference between phenotype frequency and predicted phenotype frequency based on the frequency of LP-associated alleles. As above, we assumed Hardy-Weinberg equilibrium and performed surface interpolation using the data provided in the tables of Additional Files 1 and 2 . We then subtracted the surface representing expected frequencies from that representing observed LP frequencies. Maps were plotted using PyNGL [33]. The code for the program is available from the authors.

\section{GenoPheno Correlation Analysis}

To identify regions where LP-associated allele frequencies are insufficient to explain observed LP incidence we applied the Monte Carlo based statistical test GenoPheno [8] to each cell in a 198 (west-east) by 119 (south-north) grid of covering the Old World. For each cell it was necessary to provide information on LP-associated allele frequencies and LP incidence (see above) as well as on sample numbers used for each data type and type I and type II error rates for the LP phenotype tests used. These parameters were estimated by surface interpolating values from genetic and phenotypic studies to provide 6 surface interpolated 'layers' of information. The code for the program is available from the authors.

\section{Similar Populations at Similar Regions Analysis}

To demonstrate LP specific genotype-phenotype correlation analysis without interpolation (Table 1) we have performed quantitative difference and GenoPheno tests (as described above) on phenotype and genotype data 
Table 1 The GenoPheno correlation for similar ethnic groups at similar regions

\begin{tabular}{|c|c|c|c|c|c|c|c|c|c|c|c|c|}
\hline \multirow{2}{*}{ Continent } & \multicolumn{2}{|l|}{ Population } & \multicolumn{4}{|c|}{$\begin{array}{l}\text { Lactase persistence } \\
\text { genotype data }\end{array}$} & \multicolumn{4}{|c|}{$\begin{array}{l}\text { Lactase persistence } \\
\text { phenotype data }\end{array}$} & \multicolumn{2}{|c|}{$\begin{array}{l}\text { Genotype-phenotype } \\
\text { correlation }\end{array}$} \\
\hline & Country & Population & $\mathrm{N}$ & $\begin{array}{l}\text { Sum of LP- } \\
\text { associated } \\
\text { alleles } \\
\text { frequency }\end{array}$ & $\begin{array}{l}\text { Predicted } \\
\text { LP freq. }\end{array}$ & Ref. & $\mathrm{N}$ & $\begin{array}{l}\text { Pheno. } \\
\text { Freq. }\end{array}$ & $\begin{array}{l}\text { Testing } \\
\text { method }\end{array}$ & Ref. & $\begin{array}{l}\text { GenoPheno } \\
\text { P-value }\end{array}$ & $\begin{array}{l}\text { Genotype - } \\
\text { phenotype } \\
\text { quantitative } \\
\text { difference }\end{array}$ \\
\hline Africa & Nigeria & Yoruba & 50 & 0.00 & 0.00 & [18] & 48 & 0.17 & $B G$ & {$[43]$} & 0.5670 & 0.17 \\
\hline Africa & Senegal & Wolof & 118 & 0.00 & 0.00 & {$[24]$} & 53 & 0.51 & $B G$ & {$[44]$} & $<0.00005$ & 0.51 \\
\hline Africa & Sudan & Beni Amer & 162 & 0.26 & 0.45 & [24] & 40 & 0.88 & $\mathrm{BH}$ & {$[45]$} & $<0.00005$ & 0.42 \\
\hline Africa & Uganda & Bantu & 44 & 0.00 & 0.00 & [8] & 17 & 0.06 & $B G$ & {$[46]$} & 0.7552 & 0.06 \\
\hline Asia & China & Kazakh & 94 & 0.00 & 0.00 & {$[47]$} & 195 & 0.24 & $\mathrm{BH}$ & {$[48]$} & 0.0026 & 0.24 \\
\hline Asia & India & Indian & 68 & 0.07 & 0.14 & {$[7]$} & 38 & 0.00 & BIOPSY & [49] & 0.0024 & -0.14 \\
\hline Asia & Japan & Japanese & 62 & 0.00 & 0.00 & [18] & 40 & 0.28 & $B G$ & {$[50]$} & 0.0432 & 0.28 \\
\hline Asia & North India & $\begin{array}{l}\text { Northern } \\
\text { Indian }\end{array}$ & 128 & 0.33 & 0.55 & {$[7]$} & 136 & 0.55 & $B G$ & {$[51,52]$} & 1.0000 & 0.00 \\
\hline Asia & Russia & Komi & 20 & 0.15 & 0.28 & [23] & 56 & 0.38 & $B G$ & [53] & 0.9248 & 0.10 \\
\hline Europe & Finland & Finns & 1876 & 0.58 & 0.82 & [23] & 638 & 0.83 & BIOPSY & {$[54]$} & 0.3686 & 0.01 \\
\hline Europe & Greece & Greek & 100 & 0.09 & 0.17 & [40] & 200 & 0.25 & $\mathrm{BH}$ & {$[55]$} & 0.8136 & 0.08 \\
\hline Europe & Hungary & Hungarian & 110 & 0.62 & 0.86 & [56] & 262 & 0.59 & $\mathrm{BH}$ & [57] & $<0.00005$ & -0.26 \\
\hline Europe & Ireland & Irish & 65 & 0.95 & 1.00 & {$[8]$} & 50 & 0.96 & $B G$ & {$[58]$} & 0.6014 & -0.04 \\
\hline Europe & Italy & Sardinian & 153 & 0.07 & 0.14 & {$[40]$} & 47 & 0.15 & $\mathrm{BH}$ & [59] & 0.5530 & 0.01 \\
\hline Europe & Italy & North Italian & 28 & 0.36 & 0.59 & [18] & 208 & 0.49 & $\mathrm{BH}$ & {$[60]$} & 0.3348 & -0.10 \\
\hline Europe & Italy & $\begin{array}{l}\text { Central } \\
\text { Italian }\end{array}$ & 98 & 0.11 & 0.21 & [40] & 65 & 0.82 & $B G$ & {$[61]$} & $<0.00005$ & 0.61 \\
\hline Europe & Italy & $\begin{array}{l}\text { Southern } \\
\text { Italian }\end{array}$ & 189 & 0.08 & 0.15 & {$[40]$} & 99 & 0.46 & $\mathrm{BH}$ & {$[62]$} & $<0.00005$ & 0.31 \\
\hline $\begin{array}{l}\text { Near/ } \\
\text { Middle } \\
\text { East }\end{array}$ & Afghanistan & Tadjik & 98 & 0.30 & 0.51 & [7] & 79 & 0.18 & $\mathrm{BG}$ & {$[63]$} & $<0.00005$ & -0.33 \\
\hline $\begin{array}{l}\text { Near/ } \\
\text { Middle } \\
\text { East }\end{array}$ & Afghanistan & Pashtu & 16 & 0.10 & 0.19 & {$[18]$} & 71 & 0.21 & $B G$ & [63] & 0.3588 & 0.02 \\
\hline $\begin{array}{l}\text { Near/ } \\
\text { Middle } \\
\text { East }\end{array}$ & Iran & Iranian & 42 & 0.10 & 0.19 & [23] & 21 & 0.14 & $\mathrm{BG}$ & [64] & 0.4154 & -0.05 \\
\hline $\begin{array}{l}\text { Near/ } \\
\text { Middle } \\
\text { East }\end{array}$ & Israel & Arabs & 160 & 0.05 & 0.10 & {$[24]$} & 67 & 0.19 & $B G$ & {$[65]$} & 0.8966 & 0.10 \\
\hline $\begin{array}{l}\text { Near/ } \\
\text { Middle } \\
\text { East }\end{array}$ & Jordan & Jordanian & 112 & 0.11 & 0.20 & {$[23]$} & 162 & 0.76 & $\mathrm{BH}$ & [66] & $<0.00005$ & 0.55 \\
\hline $\begin{array}{l}\text { Near/ } \\
\text { Middle } \\
\text { East }\end{array}$ & Pakistan & Balochi & 50 & 0.00 & 0.00 & [18] & 32 & 0.38 & $\mathrm{BH}$ & {$[67]$} & 0.0036 & 0.38 \\
\hline $\begin{array}{l}\text { Near/ } \\
\text { Middle } \\
\text { East }\end{array}$ & Saudi Arabia & Bedouin & 94 & 0.48 & 0.73 & [23] & 21 & 0.81 & $\mathrm{BH}$ & {$[68]$} & 0.5166 & 0.08 \\
\hline $\begin{array}{l}\text { Near/ } \\
\text { Middle } \\
\text { East }\end{array}$ & Turkey & Turks & 98 & 0.03 & 0.06 & {$[8]$} & 126 & 0.30 & $\mathrm{BH}$ & {$[69]$} & 0.0076 & 0.24 \\
\hline
\end{tabular}

GenoPheno was used to calculate the P-value for lack of correlation between the predicted phenotype (based on all 4 known LP-associated alleles) and the observed phenotype at locations where the ethnic groups were similar, and so expected to have a good genotype-phenotype correlation. Unlike figures 5 and 6 , interpolation was not used here, but rather observed points analyses. 
(from the tables of Additional Files 1 and 2, respectively) where: (1) the ethnic groups are similar, and (2) the country/region is similar and a deviation of maximum 3 degrees between the two data points.

\section{Sample Density Analysis}

To indicate regions where genotype and phenotype sampling is sparse we used a 2-dimensional kernel density estimation [34,35], as implemented in the KernSmooth package of the $\mathrm{R}$ statistical programming environment [36]. We used an isotropic kernel with a bandwidth equal to half of the average nearest neighbour distance (ANND) between sample points, to ensure that $>95 \%$ of each Gaussian sampling region will be within the ANND.

\section{Results}

\section{Interpolated LP Phenotype Frequencies}

Figure 1 shows an interpolated map of the frequencies of LP based on phenotype tests (also see Additional File 1, [1]). Although this map should provide a reasonable representation of frequencies in Europe and western Asia, it should be noted that (1) data is sparse at eastern and northern Asia, Indonesia, Melanesia, Australia and Polynesia, and (2) in Africa and the Middle East it is often the case that populations living in close proximity to each other have dramatically different LP frequencies, depending to an extent on traditional subsistence strategies [1].

\section{Interpolated Predicted LP Phenotype Frequencies}

Figure 2 shows an interpolated map of the frequencies of LP predicted by all 4 currently known LP associated allelic variants, based on genotyping tests (see Additional File 2, $[7,8,11,18,25-27])$. As with the phenotype data, the genotype data is sparse in eastern and northern Asia, Indonesia, Melanesia, Australia and Polynesia.

Figure 3 shows an interpolated map of the frequencies of LP predicted by the $-13,910 \mathrm{C}>\mathrm{T}$ allele data only (see Additional File 2, [7,8,11,18,25-27]).

Figure 4 shows an interpolated map of the frequencies of LP predicted by the 3 currently known LP associated allelic variants, excluding the $-13,910 \mathrm{C}>\mathrm{T}$ allele (see Additional File 2, $[12,23,26,28])$. While this map provides a reasonable representation of the frequencies of the $3 \mathrm{LP}$ associated allelic variants in eastern Africa and the Middle East, data from the rest of the world is sparse.

\section{LP Genotype-Phenotype Correlations}

Figure 5 shows the quantitative difference between observed phenotype frequency and predicted phenotype frequency based on the frequency of 4 LP-associated alleles. This map was obtained by subtracting the surface shown in Figure 2 from that shown in Figure 1. It represents the extent to which current knowledge of the frequencies various LP-associated alleles explains the distribution of the LP trait. In many cases sample

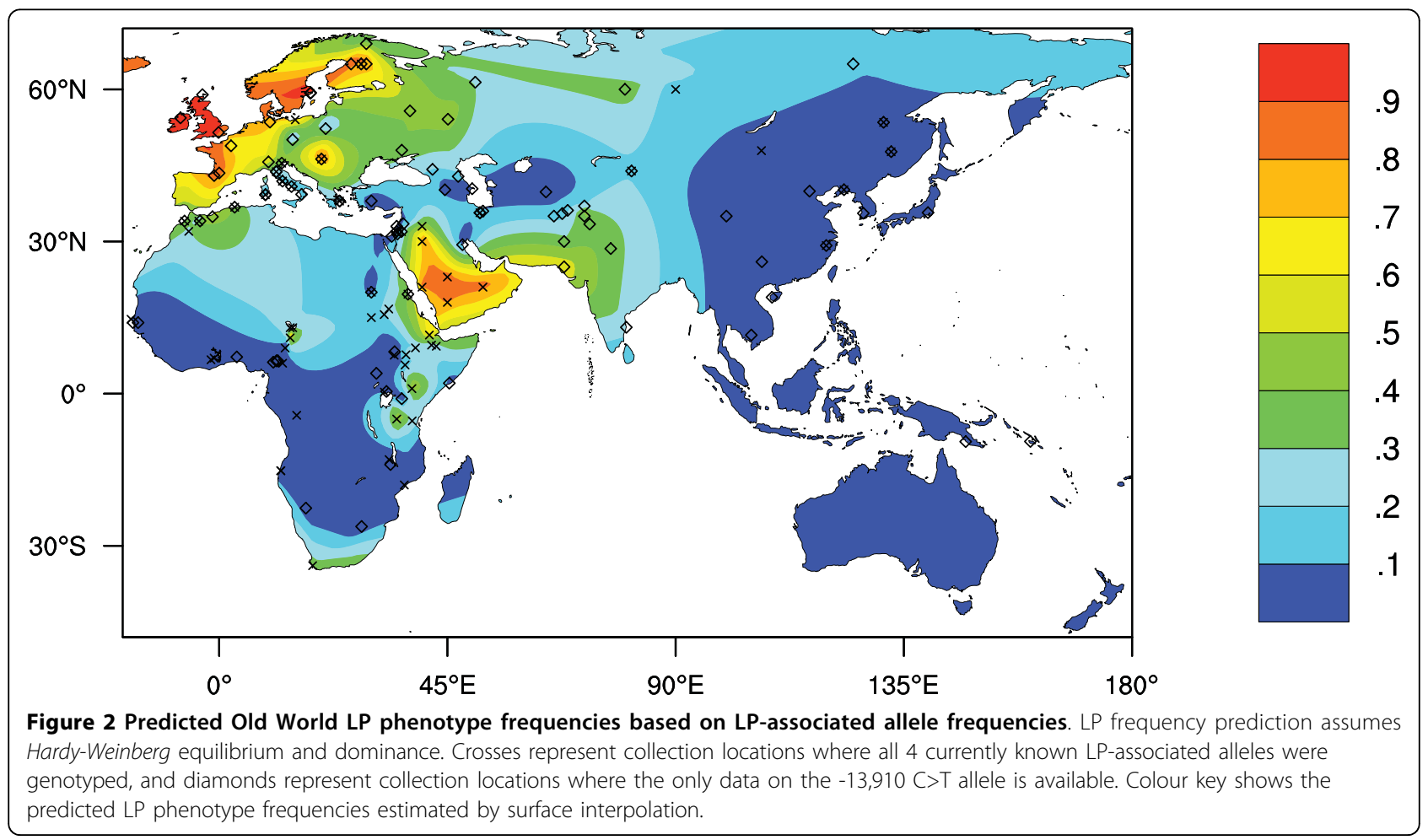




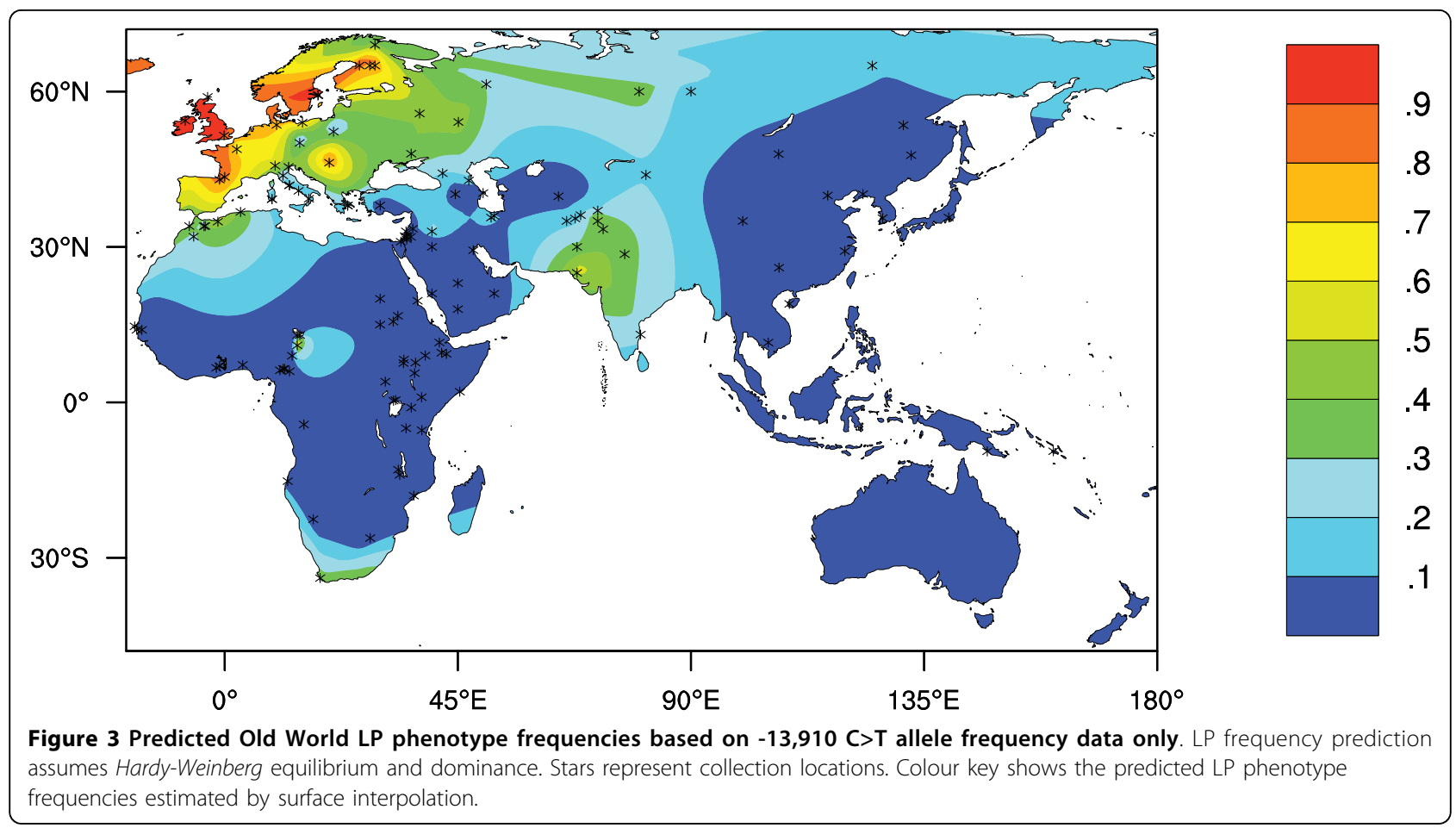

numbers used to obtain molecular and phenotype data were small. Additionally, phenotype testing error rates are appreciable. It is therefore possible that, for some regions, where the discrepancies between predicted and observed LP frequencies are high, such differences can be explained by sampling and testing errors alone.

To account for the sampling and testing errors, we have applied the Monte Carlo based statistical test GenoPheno [8] to the surfaces presented in Figures 1 and 2. Performing this test also requires data on sample numbers and error rates, for which we generated interpolated surfaces by applying the same reasoning as we have to LP frequencies. By applying the GenoPheno test to 23,562 locations on a 198 by 119 cell grid we obtain the surface presented on Figure 6 . These p-values approximate the probability of the observed genotype and phenotype data under the null hypothesis that the LP-associated alleles and phenotyping errors alone account for the observed LP frequency.

\section{Online Resource For LP Phenotype and Genotype Data and Associated Mapping}

The LP phenotype and genotype datasets are available at the GLAD (Global Lactase persistence Association Database) web site http://www.ucl.ac.uk/mace-lab/GLAD/. These datasets will be updated every three months, and the maps corresponding to Figures 1 to 6 of this article will be regenerated from those updated databases. The web pages contain guidelines for what we consider "appropriate" LP data (as described at the Methods section). We encourage readers to send us new LP genotype and phenotype data whenever it is available.

\section{Discussion}

In this study we have identified regions where the current data on LP-associated allele frequencies is insufficient to explain the estimated LP phenotype frequencies, by surface interpolating LP genotype and phenotype data. Our analyses also indicate regions where genotypic or phenotypic data is sparse or non-existent (see also the maps of Additional Files 3, 4, and 5). Data collection from these regions is likely to be of value in developing a fuller understanding of the distribution and evolution of LP. We suggest that regions where LP-associated genotypes are under-predicting LP are good candidates for further genetic studies.

We accept that surface interpolation can give misleading results when data are sparse and so urge caution in interpreting our results for such regions. The data used and maps generated will be regularly updated via the GLAD website http://www.ucl.ac.uk/mace-lab/GLAD/. We therefore expect that problems caused by interpolation over regions with sparse data will diminish as more data become available. However, to indicate regions where sampling is sparse we have generated three extra maps (Additional Files 3, 4, and 5) showing the density of sample sites for phenotypic data, for sites where 

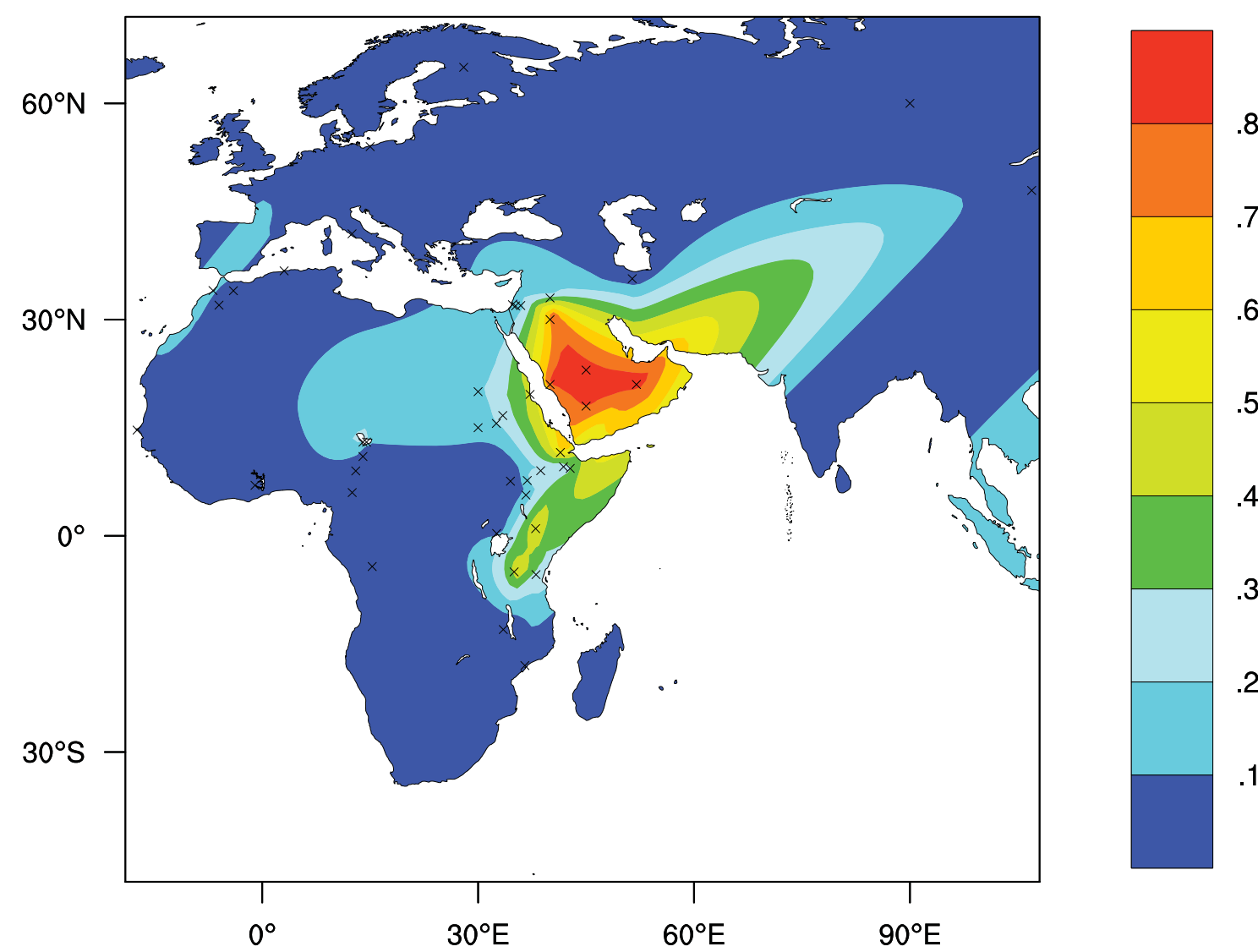

Figure 4 Predicted Old World LP phenotype frequencies based on frequency data for the currently known LP associated allelic variants, excluding the $-13,910 \mathrm{C}>\mathrm{T}$ allele. LP frequency prediction assumes Hardy-Weinberg equilibrium and dominance. Crosses represent collection locations. Colour key shows the predicted LP phenotype frequencies estimated by surface interpolation.

$-13,910 * \mathrm{~T}$ allele data is available, and for sites where data on all 4 LP-associated alleles is available, respectively. These maps were generated using 2-dimentionalkernel density estimation [34-36] with a kernel bandwidth equal to half of the average nearest neighbour distance between sample sites.

While on a broad scale most regions of the Old World have been sampled for the $-13,910 * \mathrm{~T}$ allele, data on frequencies of the other three LP-associated alleles is localised mainly to Africa and the Middle East. It is likely that further studies will identify appreciable frequencies of the $-13,907^{*} \mathrm{G},-13,915^{*} \mathrm{G}$ or $-14,010^{*} \mathrm{C}$ alleles, or reveal new LP-associated alleles, in other regions. To illustrate how data on the three non $-13,910 * \mathrm{~T}$ alleles have added to our knowledge of the genetics of LP, we have generated two additional maps: one is showing the correlation between the LP phenotype and the LP phenotype predicted by data where all 4 LP-associated alleles were sequenced (Additional File 6), and the second is showing the correlation between the LP phenotype and the LP phenotype predicted by data on the $-13,910 * \mathrm{~T}$ allele alone (Additional File 7). We then subtracted the surfaces of these two figures (Additional File 8).

Our analysis indicated a few regions (including Arabia and the Basque region) where the LP-associated allele frequency appears to over-predict LP phenotype frequency. If we assume that all four LP-associated alleles considered here are causative of the trait, or very tightly linked to causative variants, then it is likely that over-prediction is a result of population sampling problems. For example, the pastoralist Bedouin in Saudi Arabia have high frequencies of LP, while nonBedouin Arabs from the same region typically have lower frequencies [37]. Alternatively, over-prediction may to an extent arise through post weaning nongenetic causes of LP, such as secondary lactose intolerance caused by gut trauma [3-6]. To an extent these problems of matching population groups from the same geographic regions applies to our whole analysis. However, it is notable from Figure 5 that where a lack of correspondence between LP phenotype and predicted phenotype frequencies occurs, it is usually 

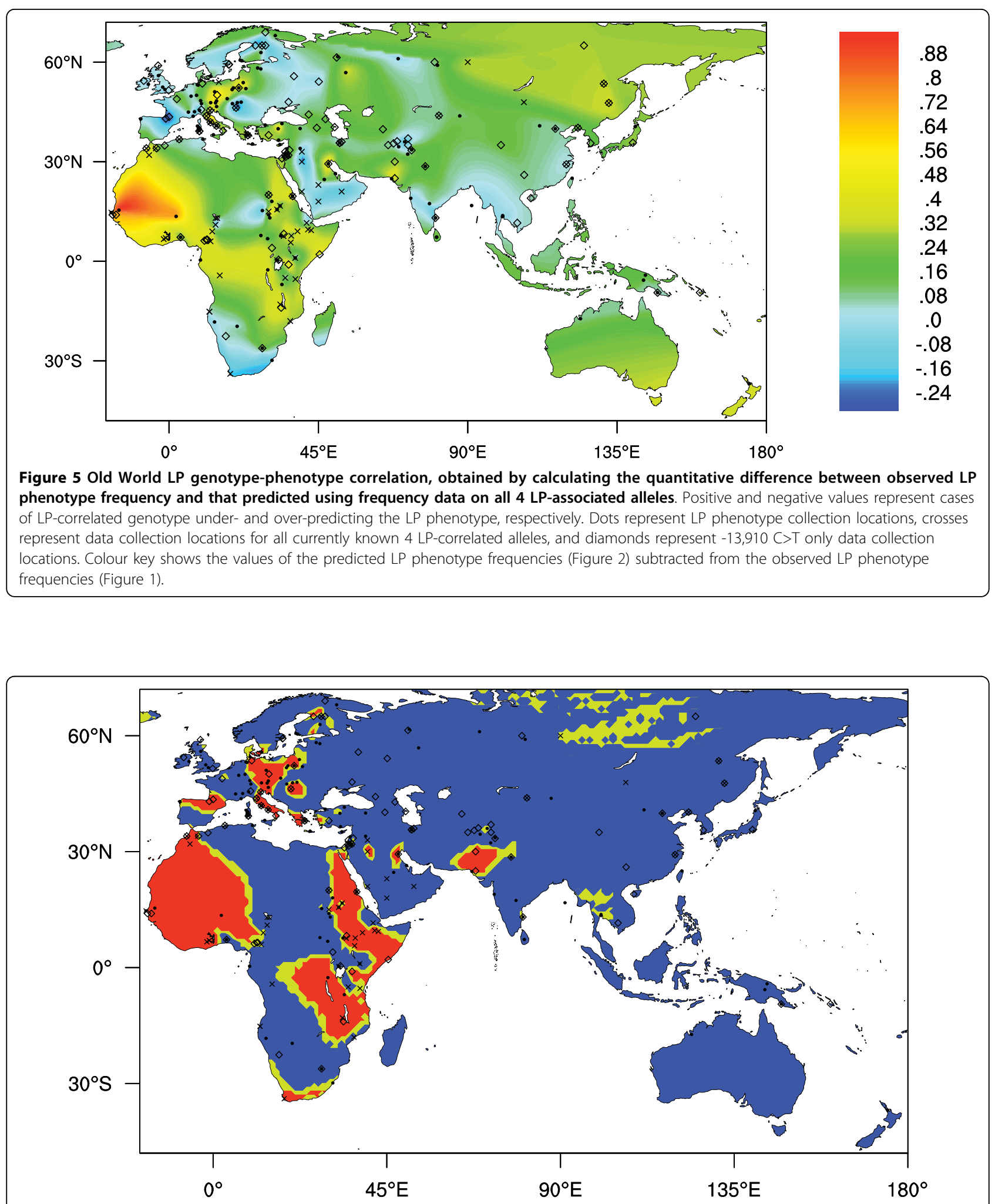

Figure 6 Old World LP genotype-phenotype correlation, obtained by the GenoPheno Monte Carlo test. Dots represent LP phenotype data collection locations, crosses represent data collection locations for all currently known 4 LP-correlated alleles, and diamonds represent collection locations for data on $-13,910$ C > T only. Colour key shows the $p$ value obtained by the GenoPheno test. Red colour represents values of $p<0.01$, indicating a highly significant lack of correlation, yellow colour represents values of $0.01 \leq p<0.05$, indicating a significant lack of correlation, and blue colour represents values of $p \geq 0.05$, indicating no significant lack of correlation. 
under-prediction (maximum $=0.94$; for West Africa), while over-prediction is rare and considerably smaller in scale (maximum $=0.29$; for the Basque region). In some cases it was possible to identify genotype and phenotype data originating from the same populations or ethnic groups. For such populations we also performed a separate GenoPheno analysis (see Table 1, [8]). We note that the large discrepancies between LP phenotype frequencies and those predicted from allele frequency data, from this analysis of 'matched' populations, mostly occur in the same regions as where large discrepancies are indicated from the interpolation analysis (see Figure 5). This illustrates that - at a broad scale - the interpolation method that we have employed provides a reasonable approximation of where genotypic data are unable to explain the observed frequency of the LP phenotype, despite much of the data we use originating from different ethnic groups with different subsistence strategies [38,39].

By applying the GenoPheno statistical procedure to interpolated layers of phenotype and genotype associated data (Figure 6), we have identified west and parts of east Africa, eastern Europe, and parts of western, central, and southern Asia as potential targets for further genetic studies. An absence of data for the $-13,907 * \mathrm{G}$, $-13,915 * \mathrm{G}$ and $-14,010^{*} \mathrm{C}$ alleles in many of these regions may partly explain under-prediction (Figure 5 and Additional Files 6, 7, and 8). Previous studies have noted the possibility of under-prediction in eastern Europe and proposed the presence of alleles other than $-13,910 * T[40,41]$. The population sampling problems described above may also explain the under-prediction we infer in parts of southern Asia, as in each of these regions, the locations where phenotype and genotype data were obtained are mostly well separated. This population data-matching problem is, however, unlikely to explain the lack of correspondence between LP and allele frequency-based predicted LP frequencies in the region around Pakistan and Afghanistan, as well as in west Africa and Italy. Further genetic studies in these regions should prove informative.

\section{Conclusion}

In this study we have demonstrated that lactase persistence genotype data is currently insufficient to explain lactase persistence phenotype frequency in western and eastern Africa and several other Old World regions. The identification of additional LP-associated or LP-causative alleles, especially in these regions, will help not only in developing a better understanding of the evolution of LP but also in elucidating the physiological mechanisms that underlie the trait. The interpolation and mapping approach that we have applied in this study may also be of value in studying the underlying genetic basis and evolution of other phenotypic variation that impacts on human health, such as the distribution of functional variation in drug metabolising enzymes [42].

\section{Additional file 1: A table of the lactase persistence phenotype \\ frequencies. Columns show location (continent, country, longitude and latitude), population group, number of individuals tested, frequency of lactase persistent individuals, LP test method, and the primary source reference. The Americas were excluded from the table due to paucity of data. Other reasons for data exclusion were: recent immigrant populations, children (under 12 years old), or biased individuals selection criteria (such as individuals reported being lactase non persistent or related individuals). Wherever only country name was available, location was determined by the capital city or the estimated central point of the country. \\ Click here for file \\ [http://www.biomedcentral.com/content/supplementary/1471-2148-10- 36-S1.XLS ]}

Additional file 2: A table of the lactase persistence associated allele frequencies. Columns show location (continent, country, longitude and latitude), population group, number of individuals tested, frequency of $-13910^{*} \mathrm{~T},-13,907^{*} \mathrm{G},-13,915^{*} \mathrm{G}$ and $-14,010^{*} \mathrm{C}$ LP-associated alleles, the sum of all LP-associated alleles, predicted lactase persistence frequency, and the primary literature and own data source. Data taken from SNP typing tests (where only $-13,910^{*} \mathrm{~T}$ is shown) or from resequencing. The Americas were excluded from the table due to paucity of data. The predicted lactase persistence frequency was calculated by assuming Hardy-Weinberg equilibrium and dominance using the sum of the all available LP-associated alleles at a specific location. Wherever only country name was available, location was determined by the capital city or the estimated central point of the country. It should be noted that the collection location for the Indian and North Indian genotype data was Singapore. As an exception, we placed these data in the location of the ancestral population because of lack of genetic data from India.

Click here for file

[http://www.biomedcentral.com/content/supplementary/1471-2148-1036-S2.XLS ]

Additional file 3: A map of the density of sample sites for phenotypic data

Click here for file

[http://www.biomedcentral.com/content/supplementary/1471-2148-1036-S3.PDF

Additional file 4: A map of the density of sample sites where 13,910*T allele data is available.

Click here for file

[http://www.biomedcentral.com/content/supplementary/1471-2148-1036-S4.PDF ]

Additional file 5: A map of the density of sample sites where data of all 4 LP-associated alleles is available.

Click here for file

[http://www.biomedcentral.com/content/supplementary/1471-2148-1036-S5.PDF

Additional file 6: Africa and Middle East LP genotype-phenotype correlation, obtained by calculating the quantitative difference between observed phenotype frequency and predicted phenotype frequency based on locations where only fully sequenced data of all 4-LP associated alleles was available. Positive and negative values represent cases of LP-correlated genotype under- and over-predicting the LP phenotype, respectively. Dots represent LP phenotype collection locations, crosses represent data collection locations for all currently known 4 LP-correlated alleles. Colour key shows the values of the predicted LP phenotype frequencies (Figure 4) subtracted from the observed LP phenotype frequencies (Figure 1). The Asia-Pacific data was not analysed since 4 alleles data in these regions is very sparse, and fully sequenced data for western and northern Europe is also sparse. Click here for file

[http://www.biomedcentral.com/content/supplementary/1471-2148-1036-S6.PDF ] 
Additional file 7: Old World LP genotype-phenotype correlation, obtained by calculating the quantitative difference between observed phenotype frequency and predicted phenotype frequency based on $-13,910^{*} \mathrm{~T}$ allele data only. Positive and negative values represent cases of LP-correlated genotype under- and over-predicting the LP phenotype, respectively. Dots represent LP phenotype collection locations, crosses represent data collection locations for the 13,910*T allele obtained from fully sequenced data, and diamonds represent $-13,910$ C > T only data collection locations. Colour key shows the values of the predicted LP phenotype frequencies predicted by $-13,910^{*} \mathrm{~T}$ allele data only subtracted from the observed LP phenotype frequencies. Click here for file

[http://www.biomedcentral.com/content/supplementary/1471-2148-1036-S7.PDF ]

Additional file 8: The difference between the maps of Additional Files 6 and 7, demonstrating the additional knowledge acquired by the 3 additional LP-associated alleles (other than the -13,910*T allele). The Asia-Pacific data was not analysed since 4 alleles data in these regions is very sparse.

Click here for file

[http://www.biomedcentral.com/content/supplementary/1471-2148-1036-S8.PDF ]

\section{Acknowledgements}

We would like to thank Neil Bradman, Sarah Browning, Chris Plaster, Naser Ansari Pour, N. Saha, and Ayele Tarekegn for their help with the samples, as well as Charlotte Mulcare and Mike Weale who laid the foundations for this study, Pascale Gerbault, Adam Powell, and Anke Liebert for their helpful comments and suggestions and Melford Charitable Trust for support for sequencing. Yuval Itan was funded by the B'nai B'rith/Leo Baeck London Lodge and Annals of Human Genetics scholarships, Bryony L. Jones by a MRC/DTA studentship, and Catherine J.E. Ingram by a BBSRC-CASE studentship. We thank the AHRC Centre for the Evolution of Cultural Diversity (CECD) and the Centre for Mathematics and Physics in the Life Sciences and Experimental Biology (CoMPLEX), UCL, for supporting this research.

\section{Author details}

'Research Department of Genetics, Evolution and Environment, University College London, London WC1E 6BT, UK. ${ }^{2}$ CoMPLEX (Centre for Mathematics \& Physics in the Life Sciences and Experimental Biology), University College London, London WC1E 6BT, UK. ${ }^{3}$ AHRC Centre for the Evolution of Cultural Diversity, Institute of Archaeology, University College London, 31-34 Gordon Square, London WC1H OPY, UK.

\section{Authors' contributions}

$\mathrm{YI}$ and MGT initiated and designed the study. YI performed the analyses and the programming routines. MGT contributed biological, statistical, and anthropological expertise. DMS contributed lactase persistence genotype and phenotype expertise. YI, DMS, BLI, and CJEl contributed to collating the data and editing the tables. YI and MGT wrote the article. All authors contributed in revising the article. All authors read and approved the final manuscript.

Received: 28 July 2009

Accepted: 9 February 2010 Published: 9 February 2010

\section{References}

1. Ingram CJ, Mulcare CA, Itan Y, Thomas MG, Swallow DM: Lactose digestion and the evolutionary genetics of lactase persistence. Hum Genet 2009, 124(6):579-591.

2. Heyman MB: Lactose intolerance in infants, children, and adolescents. Pediatrics 2006, 118(3):1279-1286.

3. Newcomer AD, McGill DB, Thomas PJ, Hofmann AF: Prospective comparison of indirect methods for detecting lactase deficiency. N Engl J Med 1975, 293(24):1232-1236.

4. Peuhkuri K: Lactose, lactase, and bowel disorders. Helsinki: University of Helsinki 2000.
5. Gudmand-Hoyer E, Skovbjerg H: Disaccharide digestion and maldigestion. Scand I Gastroenterol Suppl 1996, 216:111-121.

6. Swallow DM: Genetics of lactase persistence and lactose intolerance. Annu Rev Genet 2003, 37:197-219.

7. Mulcare CA: The evolution of the lactase persistence phenotype. London: University of London 2006.

8. Mulcare CA, Weale ME, Jones AL, Connell B, Zeitlyn D, Tarekegn A Swallow DM, Bradman N, Thomas MG: The T allele of a single-nucleotide polymorphism $13.9 \mathrm{~kb}$ upstream of the lactase gene (LCT) (C-13.9kbT) does not predict or cause the lactase-persistence phenotype in Africans. Am J Hum Genet 2004, 74(6):1102-1110.

9. Rasinpera H, Savilahti E, Enattah NS, Kuokkanen M, Totterman N, Lindahl H, Jarvela I, Kolho KL: A genetic test which can be used to diagnose adulttype hypolactasia in children. Gut 2004, 53(11):1571-1576.

10. Swallow DM: DNA test for hypolactasia premature. Gut 2004, 55:131-132

11. Ingram CJ, Elamin MF, Mulcare CA, Weale ME, Tarekegn A, Raga TO, Bekele E, Elamin FM, Thomas MG, Bradman N, et al: A novel polymorphism associated with lactose tolerance in Africa: multiple causes for lactase persistence?. Hum Genet 2007, 120(6):779-788.

12. Tishkoff SA, Reed FA, Ranciaro A, Voight BF, Babbitt CC, Silverman JS, Powell K, Mortensen HM, Hirbo JB, Osman M, et al: Convergent adaptation of human lactase persistence in Africa and Europe. Nat Genet 2007, 39(1):31-40.

13. Enattah NS, Sahi T, Savilahti E, Terwilliger JD, Peltonen L, Jarvela I: Identification of a variant associated with adult-type hypolactasia. Nat Genet 2002, 30(2):233-237.

14. Lewinsky RH, Jensen TG, Moller J, Stensballe A, Olsen J, Troelsen JT: T13910 DNA variant associated with lactase persistence interacts with Oct-1 and stimulates lactase promoter activity in vitro. Hum Mol Genet 2005, 14(24):3945-3953

15. Kuokkanen M, Enattah NS, Oksanen A, Savilahti E, Orpana A, Jarvela I: Transcriptional regulation of the lactase-phlorizin hydrolase gene by polymorphisms associated with adult-type hypolactasia. Gut 2003, 52(5):647-652.

16. Olds LC, Sibley E: Lactase persistence DNA variant enhances lactase promoter activity in vitro: functional role as a cis regulatory element. Hum Mol Genet 2003, 12(18):2333-2340.

17. Wang Y, Harvey CB, Hollox EJ, Phillips AD, Poulter M, Clay P, WalkerSmith JA, Swallow DM: The genetically programmed down-regulation of lactase in children. Gastroenterology 1998, 114(6):1230-1236.

18. Bersaglieri T, Sabeti PC, Patterson N, Vanderploeg T, Schaffner SF, Drake JA Rhodes M, Reich DE, Hirschhorn JN: Genetic signatures of strong recent positive selection at the lactase gene. Am J Hum Genet 2004, 74(6):1111-1120

19. Coelho M, Luiselli D, Bertorelle G, Lopes Al, Seixas S, Destro-Bisol G, Rocha J: Microsatellite variation and evolution of human lactase persistence. Hum Genet 2005, 117(4):329-339.

20. Burger J, Kirchner M, Bramanti B, Haak W, Thomas MG: Absence of the lactase-persistence-associated allele in early Neolithic Europeans. Proc Natl Acad Sci USA 2007, 104(10):3736-3741.

21. Itan Y, Powell A, Beaumont MA, Burger J, Thomas MG: The origins of lactase persistence in Europe. PLoS Comput Biol 2009, 5(8):e1000491.

22. Gerbault P, Moret C, Currat M, Sanchez-Mazas A: Impact of selection and demography on the diffusion of lactase persistence. PLoS One 2009, 4(7): e6369.

23. Enattah NS, Jensen TG, Nielsen M, Lewinski R, Kuokkanen M, Rasinpera $H$, El-Shanti $\mathrm{H}$, Seo JK, Alifrangis M, Khalii IF, et al: Independent introduction of two lactase-persistence alleles into human populations reflects different history of adaptation to milk culture. Am J Hum Genet 2008, 82(1):57-72

24. Ingram CJ, Raga TO, Tarekegn A, Browning SL, Elamin MF, Bekele E, Thomas MG, Weale ME, Bradman N, Swallow DM: Multiple Rare Variants as a Cause of a Common Phenotype: Several Different Lactase Persistence Associated Alleles in a Single Ethnic Group. Journal of Molecular Evolution 2009, 69(6):579-588.

25. Enattah NS, Trudeau A, Pimenoff V, Maiuri L, Auricchio S, Greco L, Rossi M, Lentze M, Seo JK, Rahgozar S, et al: Evidence of still-ongoing convergence evolution of the lactase persistence T-13910 alleles in humans. Am J Hum Genet 2007, 81(3):615-625.

26. Ingram CJ: The evolutionary genetics of lactase persistence in Africa and the Middle East. London: University of London 2008. 
27. Almon R, Engfeldt P, Tysk C, Sjostrom M, Nilsson TK: Prevalence and trends in adult-type hypolactasia in different age cohorts in Central Sweden diagnosed by genotyping for the adult-type hypolactasia-linked LCT -13910 C > T mutation. Scand J Gastroenterol 2007, 42(2):165-170.

28. Myles S, Bouzekri N, Haverfield E, Cherkaoui M, Dugoujon JM, Ward R: Genetic evidence in support of a shared Eurasian-North African dairying origin. Hum Genet 2005, 117(1):34-42.

29. Sibson R: A brief description of natural neighbor interpolation. Interpreting Multivariate Data (Probability \& Mathematical Statistics) John Wiley \& SonsBarnett V 1981, 21-36.

30. Watson D: Contouring: A Guide to the Analysis and Display of Spatial Data. Pergamon 1992.

31. Python Programming Language. http://www.python.org/.

32. Watson D: nngridr: An implementation of natural neighbour implementation. David Watson 1994, 1.

33. PyNGL. http://www.pyngl.ucar.edu/.

34. Wand MP: Fast computation of multivariate kernel estimators. Journal of Computational and Graphical Statistics 1994, 3:433-445.

35. Wand MP, Jones MC: Kernel Smoothing. Chapman \& Hall 1994

36. Wand MP, Ripley B: KernSmooth. Functions for kernel smoothing for Wand \& Jones (1995). 2009http://cran.r-project.org/web/packages/ KernSmooth/index.html.

37. Hijazi SS, Abulaban A, Ammarin Z, Flatz G: Distribution of adult lactase phenotypes in Bedouins and in urban and agricultural populations of Jordan. Tropical \& Geographical Medicine 1983, 35:157-161.

38. Blench R: Archaeology, Language, and the African Past. AltaMira Press, U. S. 2006

39. Tishkoff SA, Reed FA, Friedlaender FR, Ehret C, Ranciaro A, Froment A, Hirbo JB, Awomoyi AA, Bodo JM, Doumbo O, et al: The genetic structure and history of Africans and African Americans. Science 2009, 324(5930):1035-1044.

40. Anagnostou P, Battaggia C, Coia V, Capelli C, Fabbri C, Pettener D, DestroBisol G, Luiselli D: Tracing the distribution and evolution of lactase persistence in Southern Europe through the study of the T(-13910) variant. Am J Hum Biol 2009, 21(2):217-219.

41. Mottes M, Belpinati F, Milani M, Saccomandi D, Petrelli E, Calacoci M, Chierici R, Pignatti PF, Borgna-Pignatti C: Genetic testing for adult-type hypolactasia in Italian families. Clin Chem Lab Med 2008, 46(7):980-984.

42. Xie HG, Kim RB, Wood AJ, Stein CM: Molecular basis of ethnic differences in drug disposition and response. Annu Rev Pharmacol Toxicol 2001, 41:815-850.

43. Olatunbosun DA, Kwaku Adadevoh B: Lactase deficiency in Nigerians. Am J Dig Dis 1971, 16(10):909-914.

44. Arnold J, Diop M, Kodjovi M, Rozier J: L'intolerance au lactose chez l'adulte au Senegal. C R Seances Soc Biol Fil 1980, 174:983-992.

45. Bayoumi RA, Flatz SD, Kuhnau W, Flatz G: Beja and Nilotes: nomadic pastoralist groups in the Sudan with opposite distributions of the adult lactase phenotypes. Am J Phys Anthropol 1982, 58(2):173-178.

46. Cook GC, Kajubi SK: Tribal incidence of lactase deficiency in Uganda. Lancet 1966, 1(7440):725-729.

47. Sun HM, Qiao YD, Chen F, Xu LD, Bai J, Fu SB: The lactase gene -13910T allele can not predict the lactase-persistence phenotype in north China. Asia Pac J Clin Nutr 2007, 16(4):598-601.

48. Wang YG, Yan YS, Xu JJ, Du RF, Flatz SD, Kuhnau W, Flatz G: Prevalence of primary adult lactose malabsorption in three populations of northern China. Hum Genet 1984, 67(1):103-106.

49. Swaminathan N, Mathan VI, Baker SJ, Radhakrishnan AN: Disaccharidase levels in jejunal biopsy specimens from American and south Indian control subjects and patients with tropical sprue. Clin Chim Acta 1970 30(3):707-712

50. Yoshida Y, Sasaki G, Goto S, Yanagiya S, Takashina K: Studies on the etiology of milk intolerance in Japanese adults. Gastroenterol Jpn 1975, 10(1):29-34.

51. Gupta PS, Misra RC, Sarin GS, Ramachandran KA, Chuttani HK: Intestinal disaccharidases activity in normal adult population in tropics. J Trop Med Hyg 1971, 74(10):225-229.

52. Tandon RK, Joshi YK, Singh DS, Narendranathan M, Balakrishnan V, Lal K: Lactose intolerance in North and South Indians. Am J Clin Nutr 1981, 34(5):943-946

53. Kozlov Al: Hypolactasia in the indigenous populations of northern Russia. Int J Circumpolar Health 1998, 57(1):18-21.
54. Jussila J: Milk intolerance and lactose malabsorption in hospital patients and young servicemen in Finland. Ann Clin Res 1969, 1(3):199-207.

55. Ladas S, Papanikos J, Arapakis G: Lactose malabsorption in Greek adults: correlation of small bowel transit time with the severity of lactose intolerance. Gut 1982, 23(11):968-973.

56. Nagy D, Bogacsi-Szabo E, Varkonyi A, Csanyi B, Czibula A, Bede O, Tari B, Rasko I: Prevalence of adult-type hypolactasia as diagnosed with genetic and lactose hydrogen breath tests in Hungarians. Eur J Clin Nutr 2009, 63(7):909-912.

57. Czeizel A, Flatz G, Flatz SD: Prevalence of primary adult lactose malabsorption in Hungary. Hum Genet 1983, 64(4):398-401.

58. Fielding JF, Harrington MG, Fottrell PF: The incidence of primary hypolactasia amongst native Irish. Ir J Med Sci 1981, 150(9):276-277.

59. Meloni T, Colombo C, Ruggiu G, Dessena M, Meloni GF: Primary lactase deficiency and past malarial endemicity in Sardinia. Ital J Gastroenterol Hepatol 1998, 30(5):490-493.

60. Burgio GR, Flatz G, Barbera C, Patane R, Boner A, Cajozzo C, Flatz SD: Prevalence of primary adult lactose malabsorption and awareness of milk intolerance in Italy. Am J Clin Nutr 1984, 39(1):100-104.

61. Cavalli-Sforza LT, Strata A, Barone A, Cucurachi L: Primary adult lactose malabsorption in Italy: regional differences in prevalence and relationship to lactose intolerance and milk consumption. Am J Clin Nutr 1987, 45(4):748-754.

62. Rinaldi E, Albini L, Costagliola C, De Rosa G, Auricchio G, De Vizia B, Auricchio S: High frequency of lactose absorbers among adults with idiopathic senile and presenile cataract in a population with a high prevalence of primary adult lactose malabsorption. Lancet 1984, 1(8373):355-357.

63. Rahimi AG, Delbruck H, Haeckel R, Goedde HW, Flatz G: Persistence of high intestinal lactase activity (lactose tolerance) in Afghanistan. Hum Genet 1976, 34(1):57-62.

64. Sadre M, Karbasi K: Lactose intolerance in Iran. Am J Clin Nutr 1979 32(9):1948-1954

65. Gilat T, Malachi EG, Shochet SB: Lactose tolerance in an Arab population. Am J Dig Dis 1971, 16(3):203-206

66. Hijazi SS, Abulaban A, Ammarin Z, Flatz G: Distribution of adult lactase phenotypes in Bedouins and in urban and agricultural populations of Jordan. Trop Geogr Med 1983, 35(2):157-161.

67. Ahmad M, Flatz G: Prevalence of primary adult lactose malabsorption in Pakistan. Hum Hered 1984, 34(2):69-75.

68. Dissanayake AS, Al-Quorain AA, Al-Breiki H, El-Munshid HA, Wosornu L: Prevalence of primary adult lactose malabsorption in the Eastern Region of Saudi Arabia. Annals of Saudi Med 1990, 10:598-601.

69. Flatz G, Henze HJ, Palabiyikoglu E, Dagalp K, Turkkan T: Distribution of the adult lactase phenotypes in Turkey. Trop Geogr Med 1986, 38(3):255-258.

doi:10.1186/1471-2148-10-36

Cite this article as: Itan et al: A worldwide correlation of lactase persistence phenotype and genotypes. BMC Evolutionary Biology 2010 10:36

\section{Submit your next manuscript to BioMed Central and take full advantage of:}

- Convenient online submission

- Thorough peer review

- No space constraints or color figure charges

- Immediate publication on acceptance

- Inclusion in PubMed, CAS, Scopus and Google Scholar

- Research which is freely available for redistribution 